\title{
CARACTERÍSTICAS DOS MEMBROS DO CONSELHO DE ADMINISTRAÇÃO E SUA RELAÇÃO COM AS DECISÕES ESTRATÉGICAS DE CAPTAÇÃO DE RECURSOS: EVIDÊNCIAS EM EMPRESAS LISTADAS NA BM\&FBOVESPA
}

\author{
CHARACTERISTICS OF THE BOARD OF DIRECTORS' \\ MEMBERS AND THEIR RELATIONSHIP WITH STRATEGIC \\ DECISIONS TO RAISE FUNDS: EVIDENCE IN COMPANIES \\ LISTED ON BM\&FBOVESPA
}

\section{CARACTERÍSTICAS DE LOS MIEMBROS DEL CONSEJO DE ADMINISTRACIÓN Y SU RELACIÓN CON LAS DECISIONES ESTRATÉGICAS DE CAPTACIÓN DE RECURSOS: EVIDENCIAS EN EMPRESAS RELACIONADAS EN LA BM\&FBOVESPA}

Edicreia Andrade dos Santos

Universidade Federal de Santa Catarina (UFSC), Brasil

edicreiaandrade@yahoo.com.br

Flávio Luiz Lara

Instituto Federal do Ceará (IFCE), Brasil

flaviopf1@hotmail.com

Renata Mendes de Oliveira

Universidade Federal de Uberlândia (UFU), Brasil

remendes.itba@gmail.com

Rogério João Lunkes

Universidade Federal de Santa Catarina (UFSC), Brasil

rogeriolunkes@hotmail.com
Contextus

ISSNe 2178-9258

Organização: Comitê Científico Interinstitucional Editor Científico: Carlos Adriano Santos Gomes

Avaliação: double blind review pelo SEER/OJS Edição de texto e de layout: Carlos Daniel Andrade

Recebido em 23/03/2017

Aceito em 01/11/2017

$2^{\mathrm{a}}$ versão aceita em 10/11/2017

\begin{abstract}
RESUMO
Os membros do conselho de administração têm função importante para as estratégias gerenciais de captação de recursos, além de representarem importante mecanismo de governança corporativa, capaz de influenciar o desempenho da empresa. Sob esse contexto, o objetivo deste estudo é verificar a relação entre as características observáveis do conselho de administração e os resultados dos indicadores procedentes das estratégias e decisões relacionadas à captação de recursos. Os dados do estudo foram obtidos de 60 empresas com ações na BM\&FBovespa, entre os anos de 2011 e 2015. Dentre os resultados, observa-se que as variáveis de capitalização ajustada e seca apresentam relação mais significativa com as variáveis referentes às características dos gestores do conselho de administração. Ainda foi possível identificar a necessidade de diversificar as características dos membros da alta gestão, considerando a pequena participação de mulheres e a predominância de dirigentes mais velhos.
\end{abstract}

Palavras-chave: Conselho de administração. Captação de recursos. Desempenho. Características observáveis. BM\&FBovespa.

\section{ABSTRACT}

The board of directors' members have an important role for the management of strategies and fundraising as well as they represent an important mechanism of corporate governance, which can influence the company's performance. In this context, the object of this study is to verify the relation between the observable characteristics of the board of directors and the results of the indicators coming from the strategies and decisions associated to 
fundraising. The data were obtained from 60 companies with shares in the BM\&FBovespa stock exchange between the years 2011 and 2015. Among the results it is observed that the adjusted and dry capitalization variables present a more significant relation with the variables related to the characteristics of the administrative council's managers. It was also possible to identify the necessity to diversify the characteristics of the members in the top management, considering the small participation of women and the predominance of older managers.

Keywords: Board of Directors. Fundraising. Performance. Observable characteristics. BM\&FBovespa.

\section{RESUMEN}

Los miembros del consejo de administración tienen una función importante para las estrategias gerenciales de captación de recursos, además de representar un importante mecanismo de gobernabilidad corporativa, que puede influenciar el desempeño de la empresa. En ese contexto, el objetivo de este estudio es investigar la relación entre las características observables del consejo de administración y los resultados de indicadores provenientes de las estrategias y decisiones relacionadas a la captación de recursos. Los datos del estudio fueron obtenidos de 60 empresas con acciones en la BM\&FBovespa, entre los años de 2011 y 2015. De los resultados, son observadas que las variables de capitalización ajustada y seca tienen relación más significativa con las variables referentes a las características de los gestores del consejo de administración. Tambíen fue posible identificar la necesidad de diversificación de las características de los miembros de la alta gestión, llevando en cuenta la pequeña participación de mujeres y la predominancia de dirigentes mayores.

Palabras clave: Consejo de administración. Captación de recursos. Desempeño. Características observables. BM\&FBovespa.

\section{INTRODUÇÃ̃O}

$\mathrm{Na}$ busca por explicações para o desempenho empresarial, determinados estudos apontam o conceito de estratégia como bastante significativo para o sucesso das organizações. A Teoria dos Escalões Superiores (TES), por exemplo, tem trazido novos conhecimentos acerca das características dos altos executivos e os relacionado com as estratégias organizacionais e o desempenho das empresas (HAMBRICK; MASON, 1984; BIGUETI, 2007; HAMBRICK, 2007; BORTOLUZZI et al., 2016).

Para Hambrick (2007), existem três conjuntos de fatores intrínsecos aos trabalhos dos altos executivos: os desafios de tarefas relacionadas com as dificuldades das condições estratégicas; os desafios para um bom desempenho visando atender as exigências dos proprietários; e as aspirações de execução para propiciar um desempenho máximo que reflita as origens e disposições de cada gestor. Esses fatores indicam características peculiares dos altos executivos e retratam aspectos da TES, tanto na equipe quanto individualmente.

De acordo com Fama e Jensen (1983), o processo decisório envolve quatro etapas que a alta gestão deve observar: (i) iniciação, (ii) ratificação, (iii) execução e (iv) monitoramento. Dessas, apenas a ratificação e o monitoramento são de exclusividade do Conselho de Administração, a serem divididas entre o presidente (chairman) e o principal diretor executivo (chief executive officer-CEO).

As demonstrações contábeis apresentam variáveis que passaram por cálculos e interpretações de indicadores 
financeiros com o propósito de analisar e monitorar o desempenho da empresa (GITMAN, 2004; ASSIS, 2014). Nesses termos, os indicadores econômicofinanceiros desempenham papel importante para os analistas e o conselho de administração, por possibilitarem a mensuração, a comparação e $\mathrm{o}$ desenvolvimento de desempenhos econômicos, financeiros e patrimoniais.

Assis (2014) destaca que há uma correlação positiva e significativa entre os indicadores econômico-financeiros e o desempenho de ações no mercado de capitais. A autora também observou a falta de consenso sobre quais são os indicadores com maior poder preditivo. Contudo, a utilização de indicadores econômicofinanceiros em estudos a respeito do desempenho das empresas já ocorre há mais de um século (TAVARES; SILVA, 2012). As pesquisas não se resumem ao método de cálculo dos indicadores, mas também apontam a relevância deles como ferramentas para avaliação de desempenho e para interpretações estratégicas que possibilitam o desenvolvimento das empresas.

Na visão de Dani et al. (2017), os indicadores de desempenho empresarial são elaborados com o propósito de fornecer suporte necessário aos tomadores de decisão. Os indicadores de estrutura de capital, por exemplo, são utilizados para evidenciar a situação de endividamento organizacional, revelando se existe maior participação do capital próprio ou de terceiros (IUDÍCIBUS, 2017).

Nessa direção, a presente pesquisa buscou, à luz da TES, relacionar características observáveis - idade, gênero, formação educacional - de altos executivos ou conselheiros com indicadores de captação de recursos, para verificar como essas relações podem influenciar as decisões estratégicas empresariais. A literatura acadêmica não apresenta estudos amparados pela TES sobre como as características dos altos executivos têm impacto sobre a captação de recursos nas organizações que divulgam informações no mercado acionário. Também não se volta para a interação dessas variáveis para análise estratégicas.

Diante desse quadro, a presente pesquisa apresentou a seguinte questão norteadora: qual a relação das características observáveis do conselho de administração com os resultados dos indicadores de captação de recursos? Assim, objetivou-se averiguar a existência de relação entre características observáveis dos conselheiros das empresas listadas na BM\&FBovespa, entre os anos de 2011 e 2015, com os resultados dos indicadores de captação de recursos. 
As pesquisas nacionais que analisaram a influência das características dos altos executivos acerca do comportamento estratégico (BIGUETI, 2007; ASSIS, 2014; BORTOLUZZI et al. 2016; BORTOLUZZI, 2017), bem como as pesquisas internacionais (HAMBRICK; MASON, 1984; CARPENTER; GELETKANYCZ; SANDERS， 2004; HAMBRICK, 2007; AMRAN et al., 2014) contrastaram organizações do mesmo setor econômico. Dessa forma, justifica-se a preferência por um único setor para averiguação do desempenho das empresas em relação aos indicadores de captação de recursos

O presente estudo se justifica ainda pela relevância do tema para a academia, para os profissionais do mercado acionário e para os investidores. Além disso, a escolha de um setor específico da BM\&FBovespa baseia-se na ideia de que os conselhos de administração das empresas de consumo cíclico possuem especificidades estratégicas. Assim, devem-se observar questões relacionadas às características que podem afetar: a qualidade da administração, a concorrência, os fornecedores, os clientes, os indicadores econômico-financeiros que retratam o nível de endividamento da empresa e o grau de dependência entre fontes internas e externas de recursos, capaz de afetar as decisões estratégicas da empresa.

\section{REFERENCIAL TEÓRICO}

\subsection{Indicadores econômico- financeiros}

A análise dos indicadores econômico-financeiros visa apoiar os altos gestores nas decisões estratégicas, minimizando decisões que possam prejudicar o desempenho das organizações. Para Maximiano (2000), as decisões estratégicas possuem alto nível de incerteza por não serem programadas e por poderem afetar o desempenho organizacional, a sobrevivência e o crescimento no longo prazo das empresas.

O impacto das informações contábeis tem sido alvo de discussão no mercado financeiro a fim de verificar como podem ocasionar consequências econômicas às empresas tais como: redução dos custos de capital, redução da assimetria de informação entre gestores e fornecedores externos de capital, melhoria da eficiência nos investimentos e na alocação do capital, aumento da mobilidade internacional do capital e aumento da liquidez no mercado de ações (MAZZIONI; DIEL; OLIVEIRA, 2016). 
Os investidores interessados em obter alta rentabilidade precisam conhecer as variáveis internas e externas da empresa que exerceram influência no valor intrínseco de suas ações, de modo a facilitar a previsão de seu desempenho. Em outras palavras, precisam adotar uma análise fundamentalista (ASSIS, 2014). Sobre esse tipo de análise, Rostagno, Soares e Soares (2008) destacaram que engloba a utilização de informações contidas nos relatórios e nas demonstrações financeiras atuais e passadas, bem como dados macro- e microeconômicos, estratégicos e financeiros, com a finalidade de averiguar a variação de fatores capazes de interferir no equilíbrio entre oferta e demanda do mercado acionário. Portanto, devem-se apresentar informações suficientes para fundamentar as decisões.

Nessa direção, Assis (2014) argumentou que as categorias dos demonstrativos financeiros possuem relações especiais entre si. Analisá-las, além de apresentar a situação econômica financeira atualizada das empresas, pode ser de grande interesse para compará-las com as de outras empresas, com outro setor de atividade econômica ou outras empresas atuantes no país.

Maximiano (2000) descreve que as decisões estratégicas são o curso de ação das empresas em direção aos objetivos e metas organizacionais. Nesse sentido, o autor também destaca as decisões sobre investimentos (aplicação de recursos) e fontes de financiamentos (captação de recursos).

As empresas seguem uma hierarquia ao utilizar e/ou captar recursos, os fundos gerados internamente estando no topo, seguidos da emissão de debêntures e, como último recurso, da emissão de ações (MEDEIROS; DAHER, 2005). Assis (2014) elencou alguns aspectos a serem observados na utilização de indicadores tais como objetividade, mensurabilidade, compreensibilidade e comparabilidade. Esses aspectos, segundo o autor, atendem ao objetivo das demonstrações contábeis, a saber, publicar informações fidedignas e de fácil acesso aos atores como analistas, investidores e o conselho de administração.

O Centro de Pesquisas em Finanças (CEPEFIN) apontou os indicadores de análise financeira agrupados em categorias de Estratégia, de Eficiência, de Solvência, e as respectivas subcategorias Captação e Aplicação de Recursos, Receitas e Despesas, Rentabilidade, Liquidez e Gestão do Capital de Giro, fornecendo condições para se averiguar o desempenho global da empresa (ASSIS, 2014). Os indicadores de Estratégia têm o propósito de avaliar as decisões de captação e aplicação de recursos evidenciados pela empresa. 
A estrutura de capital, segundo Oliveira (2015), evidencia a proporção do capital de terceiros, representando a dívida da empresa, em relação ao capital próprio. Posto isso, o autor ainda considerou que a escolha pela forma de financiamento interfere nas oportunidades de negócio ou mesmo na sobrevivência da empresa no mercado, provocando discussões sobre a existência de uma estrutura de capital ótima. A inclusão de indicadores de captação de recursos pode fornecer resultados mais robustos para explicar o efeito dos dados estratégicos na tomada de decisão.

\subsection{Teoria dos Escalões Superiores (TES)}

Hambrick (2007) destaca a premissa central da TES ao afirmar que características como valores, experiências e personalidade influenciam significativamente as interpretações das situações que os altos executivos enfrentam ao tomar decisões nas empresas.

$\mathrm{Na}$ TES, os resultados organizacionais podem ser previstos em função de: características de base dos altos executivos, resultados de desempenho e decisões estratégicas que representam seus valores e percepções (HAMBRICK; MASON, 1984; CARPENTER; GELETKANYCZ; SANDERS， 2004;
BIGUETI, 2007). Os resultados organizacionais e a definição de estratégias podem ser compreendidos com base na interação entre, de um lado, as características observáveis e cognitivas e, do outro, os valores dos executivos envolvidos no processo decisório.

Os estudos seminais que abordaram a TES introduziram duas ideias centrais (HAMBRICK; $\quad$ MASON, 1984; CARPENTER; GELETKANYCZ; SANDERS, 2004; HAMBRICK, 2007). A primeira, concentrada nas características da equipe de gestores que estão no topo das organizações, consiste em conceber a liderança de uma organização como atividade compartilhada e complexa, que envolve aspectos cognitivos, capacidades e interações coletivas de toda equipe diretiva. Segundo a outra ideia, a utilização de características demográficas dos executivos e de informações acerca de sua função e credenciais tem uma relação significativa com os resultados e o desempenho das organizações, em que pese a frequente dificuldade de obter dados convencionais dos altos executivos das empresas. As características gerenciais observáveis envolvem variáveis como a idade, o posto funcional na organização, a formação acadêmica, os dados socioeconômicos, a situação financeira e o gênero dos altos executivos (HAMBRICK; MASON, 1984; 
BIGUETI, 2007; BORTOLUZZI et al., 2016).

O processo de decisão da alta gestão precisa, conforme Fama e Jensen (1983), ser dividido de forma que o presidente e o diretor executivo assumam a ratificação das decisões relevantes e o monitoramento da gestão. Os referidos autores elencam quatro etapas para o processo de decisão (i) iniciação, em que se expõem as propostas para utilizar e estruturar recursos dos contratos; (ii) ratificação, em que a alta gestão seleciona as iniciativas de decisão a serem implementadas; (iii) execução, em que se executam as decisões ratificadas; e, finalmente, (iv) monitoramento, em que se mede o desempenho dos agentes de decisão e se implementam recompensas. Nesse sentido, as etapas do processo de decisão descritas fortalecem a ideia de que a sobrevivência das organizações e a melhoria do desempenho organizacional está relacionada com as características observadas na TES dos altos executivos.

As características dos altos executivos correspondente aos valores cognitivos que são observáveis estão elencados, no Quadro 1, juntamente com os autores que indicam sua aplicação em pesquisas.

Quadro 1 - Trabalhos sobre algumas características observáveis da Teoria dos Escalões Superiores

\begin{tabular}{|c|c|c|}
\hline Características & Descrição conceitual & Autores \\
\hline Idade & $\begin{array}{l}\text { A idade média dos membros da } \\
\text { equipe de topo influencia o } \\
\text { desempenho da gestão empresarial e } \\
\text { as atitudes de assumir riscos. }\end{array}$ & $\begin{array}{l}\text { Hart e Mellons (1970); Child (1974); Hambrick e } \\
\text { Mason (1984); Wagner et al. (1984); Norburn e } \\
\text { Birley (1988); Bantel e Jackson (1989); Wiersema e } \\
\text { Bantel (1992); Buchholtz e Ribbens (1994); Karake } \\
\text { (1995); Kitchell (1997); Carpenter, Geletkanycz, e } \\
\text { Sanders (2004); Bigueti (2007); Bortoluzzi et al. } \\
\text { (2016); Pereira et al. (2016). }\end{array}$ \\
\hline $\begin{array}{l}\text { Experiência } \\
\text { profissional }\end{array}$ & $\begin{array}{l}\text { O maior período de experiência dos } \\
\text { gestores do alto escalão pode } \\
\text { produzir coesão social, aumentar a } \\
\text { socialização e levar a um melhor } \\
\text { desempenho empresarial. Em } \\
\text { contrapartida, um gestor que ocupa o } \\
\text { mesmo cargo por muito tempo pode } \\
\text { tornar-se obsoleto e resistir a certas } \\
\text { mudanças. }\end{array}$ & $\begin{array}{l}\text { Hambrick e Mason (1984); Norburn e Birley (1988); } \\
\text { Bantel e Jackson (1989); Eisenhardt e Schoonhoven } \\
\text { (1990); Finkelstein e Hambrick (1990); Michael e } \\
\text { Hambrick (1992); Hambrick e D’aveni (1992); } \\
\text { Wiersema e Bantel (1992); Hambrick et al. (1993); } \\
\text { Buchholtz e Ribbens (1994); Smith et al. (1994); } \\
\text { Kitchell (1997); Carpenter, Geletkanycz, e Sanders } \\
\text { (2004); Back e Smith (2007); Simsek (2007); } \\
\text { Bigueti (2007); Bortoluzzi et al. (2016); Pereira, } \\
\text { Theiss, Lunkes, Schnorrenberger e Gasparetto } \\
\text { (2016) }\end{array}$ \\
\hline
\end{tabular}




\begin{tabular}{|c|l|l|}
\hline \multirow{5}{*}{ Gênero } & $\begin{array}{l}\text { A literatura sobre as diferenças de } \\
\text { gênero fornece evidências sugerindo } \\
\text { se as mulheres ou os homens são } \\
\text { mais conservadores e qual dos dois } \\
\text { gêneros está mais disposto a correr } \\
\text { riscos. }\end{array}$ & $\begin{array}{l}\text { Lant et al (1992); Carpenter, Geletkanycz, e Sanders } \\
\text { (2004); Bigueti (2007); Darmadi (2013); Peni (2014) }\end{array}$ \\
\hline \multirow{5}{*}{ Formação } & $\begin{array}{l}\text { Os níveis educacionais dos } \\
\text { executivos podem representar um } \\
\text { alto ou baixo índice de aversão a } \\
\text { riscos e mudanças. }\end{array}$ & $\begin{array}{l}\text { Hambrick; Mason (1984); Norburn e Birley (1988); } \\
\text { (1992); Wiersema e Bantel (1992); Smith et al. } \\
\text { (1994); Rogers (1995); Kitchell (1997); Carpenter, } \\
\text { Geletkanycz, e Sanders (2004); Smith, Collins e } \\
\text { Clark (2005); Bigueti (2007); Bortoluzzi et al. } \\
\text { (2016); Pereira et al. (2016) }\end{array}$ \\
\hline
\end{tabular}

Fonte: adaptado de Bigueti (2007); Pereira et al. (2016).

Constata-se que as características apresentadas podem influenciar as decisões estratégicas da empresa por correlacionarem o talento gerencial, o conhecimento, as habilidades e os estilos cognitivos do alto escalão (HAMBRICK; MASON, 1984; BORTOLUZZI et al., 2016; PEREIRA et al., 2016).

\section{METODOLOGIA}

O presente estudo pode ser caracterizado como descritivo. A justificativa para essa classificação residiu na necessidade de coletar dados em uma amostra de empresas para investigar a relação entre as características dos gestores e as estratégias de captação de recursos nas organizações brasileiras de capital aberto, com ações negociadas na BM\&FBovespa, no período de 2011 a 2015.

A população da pesquisa compreendeu as companhias brasileiras de capital aberto com ações na BM\&FBovespa. O conjunto de empresas da amostra intencional restringiu-se àquelas não financeiras, do setor de consumo cíclico com ações na BM\&FBovespa, que apresentaram as informações necessárias para a estimação dos modelos para o período de 2011 a 2015, totalizando 5 anos, conforme o Quadro 2. 
CARACTERÍSTICAS DOS MEMBROS DO CONSELHO DE ADMINISTRAÇÃO E SUA RELAÇÃO COM AS DECISÕES ESTRATÉGICAS DE CAPTAÇÃO DE RECURSOS: EVIDÊNCIAS EM

EMPRESAS LISTADAS NA BM\&FBOVESPA

Quadro 2 - Amostra da pesquisa

\begin{tabular}{|c|l|c|l|}
\hline Item & Nome & Item & Nome \\
\hline 1 & Alpargatas SA & 31 & Kroton Educacional AS \\
\hline 2 & Arezzo Indústria e Comercio SA & 32 & Localiza Rent a Car SA \\
\hline 3 & Betapart Participações SA & 33 & Lojas Americanas AS \\
\hline 4 & B2W - Companhia Digital & 34 & Lojas Hering AS \\
\hline 5 & Bicicletas Monark SA & 35 & Lojas Renner AS \\
\hline 6 & Buettner SA Indústria e Comércio & 36 & Magazine Luiza SA \\
\hline 7 & Cambuci SA & 37 & Manuf Brinquedos Estrela SA \\
\hline 8 & Cia. Industrial Cataguases & 38 & Marisa Lojas AS \\
\hline 9 & Cia. Industrial Schlosser SA & 39 & Multiplus AS \\
\hline 10 & Cia Hering SA & 40 & Mundial SA Produtos de Consumo \\
\hline 11 & Cia de Locação das Américas & 41 & Nadir Figueiredo Indústria e Comércio SA \\
\hline 12 & Cia. de Tecidos do Norte de Minas - Coteminas & 42 & Pettenati SA Indústria Têxtil \\
\hline 13 & Cia. de Tecidos Santanense & 43 & Restoque Com. e Confecções de Roupas SA \\
\hline 14 & CVC Brasil Operadora e Agencia de Viagens SA & 44 & São Paulo Turismo SA \\
\hline 15 & Dohler SA Comércio e Indústria & 45 & Saraiva SA - Livreiros e Editores \\
\hline 16 & Dufry AG & 46 & Sauipe AS \\
\hline 17 & Empresa Nacional de Com. Redito e Particip. SA & 47 & Ser Educacional SA \\
\hline 18 & Estácio Participações SA & 48 & Smiles AS \\
\hline 19 & Fiação e Tecelagem São José SA & 49 & Somos Educação SA \\
\hline 20 & GAEC Educação SA & 50 & Springer AS \\
\hline 21 & Grazziotin SA & 51 & Springs Global Participações SA \\
\hline 22 & Grendene SA & 52 & T4F Entretenimento SA \\
\hline 23 & Guararapes Confecções SA & 53 & Tec Toy AS \\
\hline 24 & Hércules SA Fábrica de Talheres & 54 & Technos AS \\
\hline 25 & Hopi Hari SA & 55 & Teka-Tecelagem Kuehnrich S.A. \\
\hline 26 & Hotéis Othon SA & 56 & Têxtil Renauxview SA \\
\hline 27 & Hypermarcas SA & 57 & UNICASA Indústria de Móveis SA \\
\hline 28 & IGB Eletrônica SA & 58 & Globex Utilidades SA \\
\hline 29 & International Meal Co Alimentação SA & 59 & Vulcabrás Azaleia SA \\
\hline 30 & Karsten SA & 60 & Whirlpool SA \\
\hline
\end{tabular}

Fonte: dados da pesquisa (2017).

Os indicadores utilizados para

recursos podem ser visualizados no Quadro

capturar os resultados das decisões

3.

estratégicas voltadas para a captação de

Quadro 3 - Indicadores utilizados para decisões de captação de recursos

\begin{tabular}{|c|c|c|}
\hline Indicador & $\begin{array}{r}\text { Fórmula } \\
\end{array}$ & Descrição \\
\hline $\begin{array}{l}\text { Capitalização } \\
\text { ajustada }\end{array}$ & $\begin{array}{l}\text { Patrimônio líquido / passivo } \\
\text { circulante + passivo não circulante }\end{array}$ & $\begin{array}{l}\text { Indicador utilizado para comparação do volume de } \\
\text { capital próprio com o capital de terceiros }\end{array}$ \\
\hline Capitalização seca & $\begin{array}{l}\text { Patrimônio líquido - investimento / } \\
\text { passivo circulante + passivo não } \\
\text { circulante }\end{array}$ & $\begin{array}{l}\text { Indicador utilizado para comparação do volume de } \\
\text { capital próprio com o capital de terceiros, subtraindo- } \\
\text { se os investimentos }\end{array}$ \\
\hline $\begin{array}{l}\text { Endividamento } \\
\text { ajustado total }\end{array}$ & $\begin{array}{l}\text { Passivo circulante }+ \text { passivo não } \\
\text { circulante / patrimônio líquido }\end{array}$ & $\begin{array}{l}\text { Indicador utilizado para mensurar a proporção de } \\
\text { capital de terceiros em relação ao capital próprio }\end{array}$ \\
\hline $\begin{array}{l}\text { Endividamento } \\
\text { seco }\end{array}$ & $\begin{array}{l}\text { Passivo circulante + passivo não } \\
\text { circulante / patrimônio líquido - } \\
\text { investimentos }\end{array}$ & $\begin{array}{l}\text { Indicador utilizado para mensurar a proporção de } \\
\text { capital de terceiros em relação ao capital próprio, } \\
\text { subtraindo-se os investimentos }\end{array}$ \\
\hline $\begin{array}{c}\text { Captação de curto } \\
\text { prazo }\end{array}$ & $\begin{array}{l}\text { Passivo circulante / passivo } \\
\text { circulante + passivo não circulante }\end{array}$ & $\begin{array}{l}\text { Indicador utilizado para mensurar a captação de } \\
\text { recursos de terceiros de curto prazo em relação à } \\
\text { captação de recursos de terceiros total }\end{array}$ \\
\hline
\end{tabular}




\begin{tabular}{|c|c|c|}
\hline $\begin{array}{l}\text { Captação de longo } \\
\text { prazo }\end{array}$ & $\begin{array}{l}\text { Passivo não circulante / passivo } \\
\text { circulante + passivo não circulante }\end{array}$ & $\begin{array}{l}\text { Indicador utilizado para mensurar a captação de } \\
\text { recursos de terceiros de longo prazo em relação à } \\
\text { captação de recursos de terceiros total }\end{array}$ \\
\hline $\begin{array}{l}\text { Exigibilidades } \\
\text { tributárias }\end{array}$ & $\begin{array}{l}\text { Impostos, taxas e contribuições / } \\
\text { passivo circulante + passivo não } \\
\text { circulante }\end{array}$ & $\begin{array}{l}\text { Indicador utilizado para mensurar a participação das } \\
\text { exigibilidades tributárias em relação ao capital de } \\
\text { terceiros investido }\end{array}$ \\
\hline $\begin{array}{l}\text { Comprometimento } \\
\text { bancário }\end{array}$ & $\begin{array}{l}\text { Empréstimos e financiamentos }+ \\
\text { debêntures / passivo circulante }+ \\
\text { passivo não circulante }\end{array}$ & $\begin{array}{l}\text { Indicador utilizado para mensurar o quanto do capital } \\
\text { de terceiros é origem bancária, como empréstimos e } \\
\text { financiamentos }\end{array}$ \\
\hline $\begin{array}{l}\text { Comprometimento } \\
\text { com fornecedores }\end{array}$ & $\begin{array}{l}\text { Fornecedores / passivo circulante }+ \\
\text { passivo não circulante }\end{array}$ & $\begin{array}{l}\text { Indicador utilizado para mensurar as estratégias } \\
\text { comerciais de compra e ciclos financeiros }\end{array}$ \\
\hline
\end{tabular}

Fonte: adaptado de Assis (2014).

Para coleta dos dados necessários para o desenvolvimento da pesquisa, foi realizado o acesso à página da Bovespa (www.bmfbovespa.com.br). Durante o mês de janeiro de 2017, as demonstrações contábeis foram consultadas buscando viabilizar o cálculo dos indicadores de capitalização e endividamento. Além disso, durante o período que compreende outubro de 2016 a janeiro de 2017 , foram coletadas, por meio do formulário de referência de cada empresa investigada, as informações inerentes ao conselho administrativo correspondente, tais como gênero, idade e formação acadêmica.

Para a variável idade, calculou-se a média conforme os integrantes do corpo de diretores. Para a variável gênero, separaram-se os integrantes em masculinos e femininos, e levantou-se o percentual dos integrantes de cada grupo. Para a variável formação, por seu turno, foram utilizados os critérios de classificação conforme a área de formação e se o membro não tinha formação superior. Assim, calculou-se o percentual por grupos conforme a seguinte ordem: Grupo 1 - aqueles com formação em Administração; Ciências Contábeis; Comércio Exterior; Gestão de Recursos Humanos; Gestão Financeira; e Economia; Grupo 2 - os que tinham formação em outras áreas (Humanas, Exatas, Saúde); e Grupo 3 - sem formação superior.

Os dados coletados foram tabulados com auxílio do Microsoft Excel 2007 e, depois, analisados de forma quantitativa com a adoção de estatística descritiva, além dos testes LM de Breusch-Pagan, F de Chow, Hausman e regressão de dados em painel, realizados por meio do software estatístico Stata.

Em conformidade com o exposto por Fávero et al. (2009, p. 382), “a análise de dados em painel possui três abordagens mais comuns: pooled independent crosssections (ou POLS - pooled ordinary least squares), efeitos fixos e efeitos aleatórios". Deve-se ressaltar que, para atender aos pressupostos da regressão de dados em 
painel, o teste de LM de Breusch-Pagan deve ser feito para "averiguar se a variância dos resíduos que refletem as diferenças individuais é igual (POLS) ou diferente (efeitos aleatórios) de zero", assim como o teste de F de Chow é usado para "verificar se o intercepto é igual (POLS) ou diferente (efeitos fixos) para todas as cross-sections", e o Hausman permite "comparar os resultados do modelo de efeitos fixos com o de efeitos aleatórios" (VERGINI et al., 2015, p. 882).

\section{ANÁLISE E DISCUSSÃO DOS RESULTADOS}

Birigueti (2007) e Pereira et al. (2016) relataram em seus estudos que a idade dos membros da equipe de liderança exerce influência no desempenho da gestão e atitudes. Adicionalmente, Peni (2014) considerou que executivos com mais idade possuem maior experiência e com isso tendem a obter vantagens em termos de desempenho.

Quanto à presente pesquisa, foi possível identificar, em relação à variável idade, que os gestores têm, em média, 51 anos, sendo 27 anos a idade mínima e 83 anos a máxima, como pode ser observado na Tabela 1. Não se observa consenso quando se considera a relação entre idade e desempenho. Em D’Angelo et al. (2013), a idade pode ser indicador de experiência, algo útil em determinados momentos, mas capaz de sugerir pensamentos inflexíveis, conservadores, difíceis de serem desaprendidos, o que pode acabar comprometendo o desenvolvimento da empresa. Cline e Yore (2015), por sua vez, trataram a relação entre a experiência e a idade considerando que gestores mais velhos possuem mandato maior, o que é visto como algo benéfico para a empresa.

Tabela 1 - Dados descritivos das características dos gestores

\begin{tabular}{l|c|c|c|c|c}
\hline \multicolumn{1}{c|}{ 2011 a 2015 } & Média & Mediana & Máximo & Mínimo & Desvio Padrão \\
\hline Feminino & 0,0933 & 0,000 & 0,6667 & 0,000 & 0,1415 \\
\hline Masculino & 0,9133 & 1 & 1,5 & 0,3333 & 0,1452 \\
\hline Idade & 51 & 48 & 83 & 27 & 11,8424 \\
\hline Curso superior Área de Gestão e Negócios & 0,4983 & 0,5 & 1 & 0,000 & 0,2606 \\
\hline Curso superior em outras áreas & 0,4322 & 0,4444 & 1 & 0,000 & 0,2539 \\
\hline Sem curso superior & 0,0768 & 0,000 & 1 & 0,000 & 0,1886 \\
\hline
\end{tabular}

Fonte: dados da pesquisa (2017).

Quanto à variável gênero, pode-se observar, ainda na Tabela 1, que a quantidade de mulheres que atuam em cargos de diretoria, nas empresas analisadas, é significativamente inferior à de homens, apresentando uma média de $9 \%$. 
Esse fato pode ser decorrente, como já discutido por Coelho (2017), da ideia de que as mulheres ainda são sujeitas a restrições de gênero, precisando, por exemplo, dividir sua jornada de trabalho com os afazeres domésticos e cuidados com filhos e outros familiares.

Conforme se pode observar no estudo Women in Business 2015, da Grant Thornton, a baixa participação das mulheres nos cargos de gerência não é característica somente das empresas que compõem a amostra desta pesquisa, dado que, em vários países, a proporção de mulheres na liderança entre os anos de 2004 e 2014 cresceu apenas 3\%. Segundo o mesmo estudo, o Brasil ocupava, em 2014, as últimas posições do ranking, com 57\% das empresas nacionais sem nenhuma líder mulher.

Finalmente, em relação à variável formação acadêmica, pode-se observar que $49,83 \%$ dos gestores das empresas averiguadas possuem formação em cursos superiores, em especial na área de Gestão e Negócios, dentre os quais são considerados: Administração, Ciências Contábeis, Comércio Exterior, Gestão de Recursos Humanos, Gestão Financeira, Tecnologia e
Economia. O percentual dos gestores com formação superior em outras áreas como Ciências Humanas, Ciências Exatas e Saúde é bem próximo daquele do primeiro grupo: 43,22\%. Apenas 7,68\% dos gestores das empresas não possuem nenhuma formação superior.

O maior nível educacional do gestor representa um capital humano de grande valia para a empresa, considerando que, quanto maior a capacidade cognitiva e de processamento de informações, melhor será a contribuição do indivíduo para o processo de tomada de decisão (AMRAN et al., 2014).

Além das vantagens relacionadas ao nível de formação dos gestores, deve-se considerar o curso escolhido, que pode interferir no modo de gestão. Todavia, Martins (2014) apresenta que, para os cargos de conselheiros e diretores das empresas nacionais, ainda existe uma predileção para a contratação de engenheiros, mesmo após a abertura para os cursos de economia e negócios, evidenciando que os cursos de engenharia, por fazerem parte dos cursos elitizados historicamente, ainda possuem maior status. 
Tabela 2 - Dados descritivos dos indicadores

\begin{tabular}{l|c|c|c|c|c}
\hline $\mathbf{2 0 1 1}$ a 2015 & Média & Mediana & Máximo & Mínimo & Desvio-padrão \\
\hline Capitalização ajustada & 7,8028 & 0,5280 & 1116,0000 & $-6,7526$ & 67,3320 \\
\hline Capitalização seca & 7,1132 & 0,4271 & 1116,0000 & $-71,2450$ & 67,6428 \\
\hline Endividamento ajustado total & 3,1778 & 0,8319 & 508,0791 & $-271,0542$ & 41,3378 \\
\hline Endividamento seco & 2,2140 & 0,7378 & 508,0791 & $-271,0542$ & 39,7736 \\
\hline Captação de curto prazo & 1,5580 & 0,5248 & 79,8532 & 0,0000 & 7,0449 \\
\hline Captação de longo prazo & 1,1577 & 0,4387 & 65,6581 & 0,0000 & 5,2070 \\
\hline Exigibilidades tributárias & 0,0566 & 0,0000 & 2,6236 & 0,0000 & 0,2097 \\
\hline Comprometimento bancário & 1,1330 & 0,4133 & 62,8190 & 0,0000 & 5,1086 \\
\hline Comprometimento com fornecedores & 0,5217 & 0,0994 & 24,6775 & 0,0000 & 2,3007 \\
\hline
\end{tabular}

Fonte: dados da pesquisa (2017).

A Tabela 2 expõe as informações relativas aos valores médios para capitalização e endividamento das empresas analisadas. Para melhor compreensão dos valores adotados para os cálculos, deve-se averiguar o Quadro 3. A capitalização das empresas apresenta média de 7,80 entre 2011 e 2015. Quando se desconsidera o impacto dos investimentos, ou seja, na capitalização seca, a média é de 7,11. O endividamento gira em torno de $317,78 \%$, indicando que as exigibilidades da empresa são superiores aos valores representados em seu capital próprio. No endividamento seco, a média é reduzida, com o valor de 2,21.

De forma geral, foi possível observar que as empresas apresentam uma média de endividamento consideravelmente alta, fato que pode ser explicado pela crise econômica vivenciada pelas empresas brasileiras, com aumento das taxas de juros, recordes na cotação do dólar, dentre outros (ALMEIDA; NOVAES; ROCHA, 2016). Os indicadores médios de captação de recursos no curto prazo são ligeiramente superiores aos valores apresentados para as captações de longo prazo. No curto, a média de captação é de 1,56, enquanto, no longo, é de 1,16. As exigibilidades tributárias apresentam uma média relativamente baixa, com 0,06 .

$$
\text { Quanto ao comprometimento }
$$
bancário, observou-se que os valores relativos aos empréstimos e financiamentos da empresa representam a maior parte dos valores exigíveis, considerando uma média de 1,13, como já apresentado na Tabela 5 . O comprometimento com os fornecedores, por sua vez, obteve uma representatividade média de 0,52 dos valores que a empresa apresentou em suas exigibilidades, tanto de curto, quanto de longo prazos.

As características dos altos executivos influenciam o desempenho organizacional relacionados ao endividamento, comprometimento dos recursos, capitalização de recursos e outros indicadores. Desse modo, os gestores são responsáveis e devem sempre analisar bem todas as variáveis em momentos de tomada de decisão, buscando sempre a 
maximização dos resultados, bem como a continuidade do negócio.

Na Tabela 3, pode-se verificar, após a realização do teste de Hausman, que, para todas as variáveis (capitalização ajustada; capitalização seca; endividamento ajustado total; endividamento seco; captação de curto prazo; captação de longo prazo; exigibilidades tributárias; comprometimento bancário e comprometimento com fornecedores), pode-se utilizar o modelo de efeitos aleatórios. Entretanto, pelo teste de LM de
Breusch-Pagan, a adoção do efeito aleatório manteve-se apenas para capitalização ajustada, capitalização seca e exigibilidades tributárias, indicando-se para os demais a adoção do modelo estimado por mínimos quadrados ordinários $(P O L S)$. Por meio do teste $\mathrm{F}$ de Chow, a adoção de POLS é indicada para todas as variáveis, com exceção de capitalização ajustada, capitalização seca e exigibilidades tributárias, que já adotaram o efeito aleatório.

Tabela 3 - Testes para dados em painel

\begin{tabular}{|c|c|c|}
\hline Testes & Resultados & Hipóteses \\
\hline \multicolumn{3}{|c|}{ Painel A - Capitalização ajustada } \\
\hline LM de Breusch-Pagan & $\begin{array}{l}X^{2}=5,02 \\
\text { Sig. } X^{2}=0,013\end{array}$ & $\begin{array}{l}\text { A variância dos resíduos que refletem diferenças individuais é } \\
\text { diferente de zero (efeitos aleatórios). }\end{array}$ \\
\hline F de Chow & $\begin{array}{l}\mathrm{F}=2,06 \\
\text { Sig. } X^{2}=0,000\end{array}$ & $\begin{array}{l}\text { Os interceptos são diferentes para todas as cross-sections (efeitos } \\
\text { fixos). }\end{array}$ \\
\hline Teste de Hausman & $\begin{array}{l}X^{2}=9,54 \\
\text { Sig. } X^{2}=0,089\end{array}$ & O modelo de correção dos erros é adequado (efeitos aleatórios). \\
\hline \multicolumn{3}{|c|}{ Painel B - Capitalização seca } \\
\hline LM de Breusch-Pagan & $\begin{array}{l}X^{2}=5,40 \\
\text { Sig. } X^{2}=0,010\end{array}$ & $\begin{array}{l}\text { A variância dos resíduos que refletem diferenças individuais é } \\
\text { diferente de zero (efeitos aleatórios). }\end{array}$ \\
\hline F de Chow & $\begin{array}{l}F=2,07 \\
\text { Sig. } X^{2}=0,000\end{array}$ & $\begin{array}{l}\text { Os interceptos são diferentes para todas as cross-sections (efeitos } \\
\text { fixos). }\end{array}$ \\
\hline Teste de Hausman & $\begin{array}{l}X^{2}=8,75 \\
\text { Sig. } X^{2}=0,119\end{array}$ & O modelo de correção dos erros é adequado (efeitos aleatórios). \\
\hline \multicolumn{3}{|c|}{ Painel C - Endividamento ajustado total } \\
\hline LM de Breusch-Pagan & $\begin{array}{l}X^{2}=1,12 \\
\text { Sig. } X^{2}=0,281\end{array}$ & $\begin{array}{l}\text { A variância dos resíduos que refletem diferenças individuais é } \\
\text { igual a zero }(P O L S) \text {. }\end{array}$ \\
\hline F de Chow & $\begin{array}{l}\mathrm{F}=1,23 \\
\text { Sig. } X^{2}=0,152\end{array}$ & Os interceptos são iguais para todas as cross-sections $(P O L S)$. \\
\hline Teste de Hausman & $\begin{array}{l}X^{2}=4,51 \\
\text { Sig. } X^{2}=0,478\end{array}$ & O modelo de correção dos erros é adequado (efeitos aleatórios). \\
\hline \multicolumn{3}{|c|}{ Painel D - Endividamento seco } \\
\hline LM de Breusch-Pagan & $\begin{array}{l}X^{2}=0,54 \\
\text { Sig. } X^{2}=0,232\end{array}$ & $\begin{array}{l}\text { A variância dos resíduos que refletem diferenças individuais é } \\
\text { igual a zero }(P O L S) \text {. }\end{array}$ \\
\hline F de Chow & $\begin{array}{l}\mathrm{F}=1,11 \\
\text { Sig. } X^{2}=0,298\end{array}$ & Os interceptos são iguais para todas as cross-sections (POLS). \\
\hline Teste de Hausman & $\begin{array}{l}X^{2}=4,81 \\
\text { Sig. } X^{2}=0,439\end{array}$ & O modelo de correção dos erros é adequado (efeitos aleatórios). \\
\hline
\end{tabular}


(CONTINUAÇÃO)

\begin{tabular}{|c|c|c|}
\hline \multicolumn{3}{|c|}{ Painel E - Captação de curto prazo } \\
\hline LM de Breusch-Pagan & $\begin{array}{l}X^{2}=0,94 \\
\text { Sig. } X^{2}=0,601\end{array}$ & $\begin{array}{l}\text { A variância dos resíduos que refletem diferenças individuais é } \\
\text { igual a zero }(P O L S) \text {. }\end{array}$ \\
\hline F de Chow & $\begin{array}{l}F=0,00 \\
\text { Sig. } X^{2}=1,000\end{array}$ & Os interceptos são iguais para todas as cross-sections $(P O L S)$. \\
\hline Teste de Hausman & $\begin{array}{l}X^{2}=1,15 \\
\text { Sig. } X^{2}=0,949\end{array}$ & O modelo de correção dos erros é adequado (efeitos aleatórios). \\
\hline \multicolumn{3}{|c|}{ Painel F - Captação de longo prazo } \\
\hline LM de Breusch-Pagan & $\begin{array}{l}X^{2}=0,89 \\
\text { Sig. } X^{2}=0,685\end{array}$ & $\begin{array}{l}\text { A variância dos resíduos que refletem diferenças individuais é } \\
\text { igual a zero }(P O L S) \text {. }\end{array}$ \\
\hline F de Chow & $\begin{array}{l}\mathrm{F}=0,00 \\
\text { Sig. } X^{2}=1,000\end{array}$ & Os interceptos são iguais para todas as cross-sections $(P O L S)$. \\
\hline Teste de Hausman & $\begin{array}{l}X^{2}=0,39 \\
\text { Sig. } X^{2}=0,996\end{array}$ & O modelo de correção dos erros é adequado (efeitos aleatórios). \\
\hline \multicolumn{3}{|c|}{ Painel G - Exigibilidades tributarias } \\
\hline LM de Breusch-Pagan & $\begin{array}{l}X^{2}=3,65 \\
\text { Sig. } X^{2}=0,028\end{array}$ & $\begin{array}{l}\text { A variância dos resíduos que refletem diferenças individuais é } \\
\text { diferente de zero (efeitos aleatórios). }\end{array}$ \\
\hline F de Chow & $\begin{array}{l}F=1,48 \\
\text { Sig. } X^{2}=0,027\end{array}$ & $\begin{array}{l}\text { Os interceptos são diferentes para todas as cross-sections (efeitos } \\
\text { fixos). }\end{array}$ \\
\hline Teste de Hausman & $\begin{array}{l}X^{2}=3,41 \\
\text { Sig. } X^{2}=0,637\end{array}$ & O modelo de correção dos erros é adequado (efeitos aleatórios). \\
\hline \multicolumn{3}{|c|}{ Painel H - Comprometimento bancário } \\
\hline LM de Breusch-Pagan & $\begin{array}{l}X^{2}=0,01 \\
\text { Sig. } X^{2}=0,471\end{array}$ & $\begin{array}{l}\text { A variância dos resíduos que refletem diferenças individuais é } \\
\text { igual a zero }(P O L S) \text {. }\end{array}$ \\
\hline F de Chow & $\begin{array}{l}F=0,99 \\
\text { Sig. } X^{2}=0,497\end{array}$ & Os interceptos são iguais para todas as cross-sections (POLS). \\
\hline Teste de Hausman & $\begin{array}{l}X^{2}=2,06 \\
\text { Sig. } X^{2}=0,841\end{array}$ & O modelo de correção dos erros é adequado (efeitos aleatórios). \\
\hline \multicolumn{3}{|c|}{ Painel I - Comprometimento com fornecedores } \\
\hline LM de Breusch-Pagan & $\begin{array}{l}X^{2}=0,89 \\
\text { Sig. } X^{2}=0,698\end{array}$ & $\begin{array}{l}\text { A variância dos resíduos que refletem diferenças individuais é } \\
\text { igual a zero }(P O L S) \text {. }\end{array}$ \\
\hline F de Chow & $\begin{array}{l}\mathrm{F}=0,00 \\
\text { Sig. } X^{2}=1,000\end{array}$ & Os interceptos são iguais para todas as cross-sections (POLS). \\
\hline Teste de Hausman & $\begin{array}{l}X^{2}=1,48 \\
\text { Sig. } X^{2}=0,916\end{array}$ & O modelo de correção dos erros é adequado (efeitos aleatórios). \\
\hline
\end{tabular}

Fonte: dados da pesquisa (2017).

A Tabela 4 mostra a análise por meio de dados em painel. Em geral, observou-se que as únicas variáveis a apresentar uma relação $\mathrm{R}^{2}$ forte são capitalização ajustada e capitalização seca, com coeficientes de $35,7 \%$ e $35,6 \%$, respectivamente. A variável comprometimento bancário é a que possui a menor relação, apresentando coeficiente inferior a $1 \%$. Destaca-se que, quanto mais próximo de 1,0 estiver o valor de $\mathrm{R}^{2}$, mais forte a relação representada. 
Tabela 4 - Análise de dados em painel

\begin{tabular}{|c|c|c|c|c|c|c|c|c|c|c|c|}
\hline \multicolumn{12}{|c|}{ Painel A } \\
\hline \multirow{2}{*}{\multicolumn{2}{|c|}{ Variáveis }} & \multirow{2}{*}{\multicolumn{4}{|c|}{$\begin{array}{c}\text { Efeitos aleatórios } \\
\begin{array}{c}\text { Capitalização } \\
\text { ajustada }\end{array}\end{array}$}} & \multirow{2}{*}{\multicolumn{2}{|c|}{$\begin{array}{c}\text { Efeitos aleatórios } \\
\text { Capitalização } \\
\text { seca } \\
\end{array}$}} & \multirow{2}{*}{\multicolumn{2}{|c|}{$\begin{array}{c}\text { POLS } \\
\text { Endividamento } \\
\text { ajustado total } \\
\end{array}$}} & \multirow{2}{*}{\multicolumn{2}{|c|}{$\begin{array}{c}\text { POLS } \\
\begin{array}{c}\text { Endividamento } \\
\text { seco }\end{array} \\
\end{array}$}} \\
\hline & & & & & & & & & & & \\
\hline \multicolumn{2}{|c|}{ Constante } & \multicolumn{2}{|c|}{29.188} & \multicolumn{2}{|c|}{0.638} & 23.559 & 0.706 & -15.805 & 0.278 & 12.814 & 0.722 \\
\hline \multicolumn{2}{|c|}{ Feminino } & \multicolumn{2}{|c|}{107.954} & \multicolumn{2}{|c|}{0.050} & 108.797 & 0.050 & -4.529 & 0.699 & 0.509 & 0.987 \\
\hline \multicolumn{2}{|c|}{ Masculino } & \multicolumn{2}{|c|}{-38.624} & \multicolumn{2}{|c|}{0.425} & -37.295 & 0.444 & 19.282 & 0.064 & 17.362 & 0.559 \\
\hline \multicolumn{2}{|c|}{ Idade } & \multicolumn{2}{|c|}{0.101} & \multicolumn{2}{|c|}{0.847} & 0.170 & 0.747 & 0.040 & 0.753 & 0.037 & 0.889 \\
\hline \multicolumn{2}{|c|}{$\begin{array}{c}\text { Curso superior em Gestão } \\
\text { e Negócios }\end{array}$} & \multicolumn{2}{|c|}{-3.162} & \multicolumn{2}{|c|}{0.900} & -3.495 & 0.891 & 7.158 & 0.201 & 3.547 & 0.789 \\
\hline \multicolumn{2}{|c|}{$\begin{array}{c}\text { Curso superior em outras } \\
\text { áreas }\end{array}$} & 2.09 & & \multicolumn{2}{|c|}{0.933} & \multicolumn{2}{|l|}{2.621} & -8.765 & 0.242 & $10 . \overline{396}$ & 0.440 \\
\hline \multicolumn{2}{|c|}{$\begin{array}{c}\mathrm{R}^{2} \\
\mathrm{R}^{2} \text { Ajustado }\end{array}$} & \multicolumn{4}{|c|}{$\begin{array}{l}0,357 \\
0,341\end{array}$} & \multicolumn{2}{|c|}{$\begin{array}{l}0,356 \\
0,339\end{array}$} & \multicolumn{2}{|c|}{$\begin{array}{c}0,012 \\
-0,005\end{array}$} & & \\
\hline & & & & & inel $\mathbf{A}$ & A-contin & Iação & & & & \\
\hline & $P O$ & & & $P O$ & & $\begin{array}{r}\text { Efe } \\
\text { Alea }\end{array}$ & ótos & & & & \\
\hline Variáveis & $\begin{array}{l}\text { Captaç } \\
\text { curto }\end{array}$ & $\begin{array}{l}\text { ão de } \\
\text { razo }\end{array}$ & & igo & $\begin{array}{l}\text { o de } \\
\text { razo }\end{array}$ & $\begin{array}{r}\text { Exigib } \\
\text { tribu }\end{array}$ & $\begin{array}{l}\text { lidades } \\
\text { árias }\end{array}$ & $\begin{array}{r}\text { Compro } \\
\text { ban }\end{array}$ & $\begin{array}{l}\text { timento } \\
\text { rio }\end{array}$ & $\begin{array}{r}\text { Compro } \\
\text { o } \\
\text { forne }\end{array}$ & $\begin{array}{l}\text { letiment } \\
\text { m } \\
\text { dores }\end{array}$ \\
\hline Constante & 2.580 & 0.229 & 2.1 & & 0.645 & -0.275 & 0.078 & 1.626 & 0.726 & 1.170 & 0.204 \\
\hline Feminino & -2.977 & 0.069 & -1.3 & & 0.738 & 0.030 & 0.676 & -1.627 & 0.682 & -1.040 & 0.059 \\
\hline Masculino & -0.353 & 0.618 & -0.3 & & 0.930 & -0.016 & 0.680 & -0.021 & 0.996 & -0.146 & 0.652 \\
\hline Idade & -0.007 & 0.724 & -0.0 & & 0.590 & 0.005 & 0.029 & 0.001 & 0.979 & -0.002 & 0.834 \\
\hline $\begin{array}{l}\text { Curso superior } \\
\text { em Gestão e } \\
\text { Negócios } \\
\end{array}$ & 0.288 & 0.842 & 0.7 & & 0.684 & 0.099 & 0.125 & -0.455 & 0.790 & -0.231 & 0.778 \\
\hline $\begin{array}{l}\text { Curso superior } \\
\text { em outras áreas }\end{array}$ & -0.374 & 0.644 & & & 0.954 & 0.100 & 0.027 & -0.298 & 0.864 & -0.355 & 0.602 \\
\hline $\begin{array}{c}\mathrm{R}^{2} \\
\mathrm{R}^{2} \text { Ajustado }\end{array}$ & $\begin{array}{r}0,0 \\
-0,0 \\
\end{array}$ & & & $\begin{array}{r}0,0 \\
-0,0 \\
\end{array}$ & & & & & & & \\
\hline
\end{tabular}

Fonte: dados da pesquisa (2017).

Quando considerado o valor do coeficiente de determinação, $\mathrm{R}^{2}$ Ajustado, ficou evidente que $34,1 \%$ da captação de curto prazo e $33,9 \%$ da captação de longo prazo são explicados pelas variáveis de características dos gestores. Por sua vez, as variáveis endividamento (ajustado e seco), captação de recursos (curto e longo prazos) e comprometimento (bancário e com fornecedores) apresentaram coeficientes de determinação negativos, indicando que essas não puderam ser explicadas pelas variáveis relacionadas.
Ainda na Tabela 4, pode-se verificar que a variável de gênero feminino apresentou uma relação positiva e significativa com os indicadores de capitalização (ajustada e seca), enquanto, para a variável de gênero masculino, essa relação foi negativa e não significativa. Nota-se que a única relação positiva e significativa a $10 \%$ da variável de gênero masculino foi observada quando se analisou a variável endividamento ajustado. É possível atribuir a elevada quantidade de relações negativas quando do tratamento da 
variável gênero (feminino e masculino) ao fato, já observado, de que não se tem variedade de gênero na diretoria, considerando o reduzido número de mulheres em cargos do alto escalão. Essa questão foi um dos pontos críticos da governança, tanto em empresas com capital aberto, quanto naquelas de capital fechado, considerando ainda que a presenta feminina nos conselhos de administração faz parte dos princípios para uma boa governança coorporativa (SILVEIRA, 2014).

Em relação à variável idade, nota-se que a única relação positiva e significativa foi identificada na observação da variável exigibilidade tributária, sendo essa relação não significativa para as demais variáveis. Como já referenciado, a TES considera idade como uma das características que influenciam no desempenho organizacional. Entretanto, algumas pesquisas, como a desenvolvida por Oshagbemi (2004), evidenciou que a idade dos gestores poderia não influenciar em sua liderança, salientando que tanto os gestores mais jovens, quanto os mais velhos, adotam estilos de liderança diretiva e delegativa em níveis bem próximos.

Considerando a formação superior em cursos da área de gestão, não foi possível observar nenhuma relação significativa para nenhuma das variáveis, sendo ainda verificado que, para as variáveis capitalização (ajustada e seca) e comprometimento (bancário e com os fornecedores), existe um coeficiente negativo. Considerando a formação em cursos superiores de outras áreas, a única relação positiva e significativa apresentada foi em consideração à variável exigibilidade tributária, destacando-se ainda a existência de coeficientes altos e negativos para endividamento (ajustado e seco).

Uma possível justificativa para a presença de tantas relações negativas e não significativas para as variáveis relacionadas com a área de graduação dos gestores pode estar relacionada ao fato de que existem aqueles que não possuem formação em áreas de gestão e negócios. Em complemento aos relatos já apresentados de que não se observa consenso entre nível de formação dos gestores e desempenho, Bhagat, Bolton e Subramanian (2010) concluíram por uma confusa implicação de que, embora desempenhe papel importante no momento de contratação, a educação de CEOs não afeta o desempenho no longo prazo das empresas.

\section{CONCLUSÃO}

O presente estudo teve por objetivo averiguar a existência de relação entre características observáveis dos membros da diretoria das empresas listadas na 
BM\&FBOVESPA, que operam no setor de consumo cíclico, com os resultados dos indicadores de captação de recursos. Para tanto, foi considerada uma média das variáveis em um período que compreendeu os anos de 2011 a 2015.

De forma geral, os resultados da presente pesquisa evidenciaram a necessidade, abordada por estudos que trabalham com TES, em trabalhar a diversidade de gênero nos cargos de gestão. No estudo de Dezsö e Ross (2012), foi considerado que a escassez de mulheres em cargos mais altos pode impactar a competitividade organizacional, principalmente em decorrência dos benefícios advindos da diversidade de gênero. Essa diversidade não foi encontrada nas empresas que compõem a amostra do estudo, que apresentam maioria masculina.

Como já observado anteriormente, a TES considera a idade como outra variável que exerce influência sobre o desempenho organizacional. A variável de captação de longo prazo foi aquela que apresentou relação positiva com a variável idade. Em uma pesquisa desenvolvida por Brockmann e Simmonds (1997), já foi observado que os executivos com mais idade possuem uma tendência a ser mais avessos ao risco do que aqueles mais jovens, argumento validado por pesquisas mais recentes, como a desenvolvida por Choi, Saito e Silva (2015).
Por fim, considerou-se a variável de curso de formação no ensino superior, sendo possível observar a ausência de relação significativa com as variáveis relacionadas ao desempenho. A relação mais próxima foi verificada em relação ao endividamento seco e a exigibilidades tributárias com aqueles gestores que possuem curso superior em áreas distintas da área de gestão e negócios.

Os resultados aferidos pela presente pesquisa não podem ser generalizados, bem como existe uma limitação em decorrência da fraca relação entre as variáveis analisadas, o que pode estar associado ao setor empresarial observado, bem como ao perfil empresarial dos gestores do alto escalão das empresas brasileiras. Todavia, é importante considerar que muitos estudos divergem em relação às variáveis de característica do alto escalão que influenciam diretamente no desempenho organizacional. Nesse sentido, Erhardt, Werbel e Shrader (2003) apontaram os benefícios de se ter diversidade na composição dos ocupantes dos cargos de diretoria, impactando nos retornos obtidos e no desempenho geral da organização. A diversidade, segundo os autores, deve ser quanto a gênero, etnia e outros elementos demográficos.

Para futuras pesquisas, sugere-se trabalhar com uma amostra que 
compreenda empresas pertencentes a outros setores da BM\&FBovespa. Outra sugestão é adotar variáveis diferentes como, por exemplo, liquidez ou rentabilidade para relacioná-las com idade, gênero e área de formação, que por sua vez, podem ser acrescidas de informações relacionadas ao nível de formação, tempo de atuação em cargo de alta gestão e tempo de experiência no mercado. 


\section{REFERÊNCIAS}

ALMEIDA, J. S. G.; NOVAIS, L. F.; ROCHA, M. A. A fragilização financeira das empresas não financeiras no Brasil pós-crise. Campinas, SP: UNICAMP, 2016.

AMRAN, N. A.; YUSOF, M. A. M.; ISHAK, R.; ARIPIN, N. Do characteristics of CEO and Chairman influence Government-Linked Companies performance? Procedia-Social and Behavioral Sciences, v. 109, n. 2, p. 799-803, 2014.

ASSIS, A. V. Relação entre indicadores financeiros e desempenho em mercado de ações: estudo sobre empresas de Construção Civil da BM\&FBovespa. 2014. 77 f. Monografia (Graduação em Administração) - Departamento de Administração, Universidade de Brasília, Brasília, 2014.

BHAGAT, S.; BOLTON, B. J.; SUBRAMANIAN, A. CEO Education, CEO Turnover, and Firm Performance. Available at SSRN. 2010. Disponível em: <papers.ssrn.com/sol3/papers.cfm?abstract_id=1670219>. Acesso em: 15 jan. 2017.

BIGUETI, J. R. Um estudo sobre a influência dos modelos mentais compartilhados entre o chief information officer e o time de executivos da alta direção no alinhamento estratégico de sistemas de informação. 2007.96 p. Dissertação (Mestrado em Administração) - Faculdade de Economia, Administração e Contabilidade, Universidade de São Paulo, São Paulo, 2007.

BM\&FBovespa. Empresas Listadas. 2016. Disponível em: <www.bmfbovespa.com.br/pt_br/produtos/listados-a-vista-e-derivativos/rendavariavel/empresas-listadas.htm>. Acesso em: 18 dez. 2016.

BORTOLUZZI, D. A.; ZAKARIA, J.; SANTOS, E. A.; LUNKES, R. J. A influência das características dos executivos de alto escalão sobre a estrutura de capital: um estudo em empresas listadas na BM\&FBOVESPA. Revista Espacios, v. 37, p. 29-42, 2016.

BORTOLUZZI, D. A. Relação das características observáveis dos executivos do alto escalão no sistema de controle gerencial e no desempenho em hotéis do Brasil. 2017. 110 f. Dissertação (Mestrado em Administração) - Setor de Ciências Sociais Aplicadas, Universidade Federal de Santa Catarina, Florianópolis, 2017.

BROCKMANN, E. N.; SIMMONDS, O. G. Strategic decision making: the influence of CEO experience and use of tacit knowledge. Journal of Managerial Issues, v. 9, n. 4, p. 454-468, 1997. 
CARPENTER, M. A.; GELETKANYCZ, M. A.; SANDERS, W. G. Upper echelons research revisited: Antecedents, elements, and consequences of top management team composition. Journal of Management, v. 30, n. 6, p. 749-778, 2004.

CHOI, D. Y.; SAITO, R.; SILVA, V. A. B. Estrutura de capital e remuneração dos funcionários: evidência empírica no Brasil. Revista de Administração Contemporânea, v. 19, n. 2, p. 249$269,2015$.

CLINE, B. N.; YORE, A. S. Silverback CEOs: Age, experience, and firm value. Journal of Empirical Finance, v. 35, n. 1, p. 169-188, 2016.

COELHO, R. Direitos da mulher na contemporaneidade das relações de trabalho. 2017. 191 f. Dissertação (Mestrado em Direito), Universidade Católica de Brasília, Brasília, 2017.

DANI, A. C.; KAVESKI, I. D. S.; SANTOS, C. A.; LEITE, A. P. P.; CUNHA, P. R. Características do conselho de administração e o desempenho empresarial das empresas listadas no novo mercado. Revista de Gestão, Finanças e Contabilidade, v. 7, n. 1, p. 29-47, 2017.

D'ANGELO, A. et al. Geographical pathways for SME internationalization: Insights from an Italian sample. International Marketing Review, v. 30, n. 2, p. 80-105, 2013.

DEZSÖ, C. L.; ROSS, D. G. Does female representation in top management improve firm performance? A panel data investigation. Strategic Management Journal, v. 33, n. 9, p. 10721089, 2012.

ERHARDT, N. L.; WERBEL, J. D.; SHRADER, C. B. Board of Director Diversity and Firm Financial Performance. Corporate Governance: An International Review, v. 11, n. 2, p.102111, 2003.

FAMA, E. F.; JENSEN, M. C. Separation of ownership and control. Journal of Law and Economics, v. 26, n. 2, p. 301-325, 1983.

FÁVERO, L. P.; BELFIORE, P.; SILVA, F. D.; CHAN, B. L. Análise de dados: modelagem multivariada para tomada de decisões. Rio de Janeiro: Elsevier, 2009.

GITMAN, L. J. Princípios de Administração Financeira. 10. ed. São Paulo: Pearson Education do Brasil, 2004. 
GRANT THORNTON INTERNATIONAL BUSINESS REPORT. Women in business: o caminho para a liderança. 2015. Disponível em: <www.grantthornton.com.br/insights/articlesand-publications/women-in-business-2015/>. Acesso em: 20 fev. 2017.

HAMBRICK, D. C.; MASON; P. A. Upper echelon: the organization as a reflection of its top managers. Academy of Management Review, v. 9, n. 2, p.193-206, 1984.

HAMBRICK, D. C. Upper echelons theory: an update. Academy of Management Review, v. 32, n. 2, p. 334-343, 2007.

IUDÍCIBUS, S. Análise de balanços. 11. ed. São Paulo: Atlas, 2017.

MARTINS, T. J. A nova elite financeira no Brasil: jogos, estratégias e disputas entre os gerentes-engenheiros e os acionistas. Revista de Economia Política e História Econômica, v. 10, n.1, p. 116-149, 2014.

MAXIMIANO, A. C. A. Introdução à administração. 5. ed. Revista e ampliada. São Paulo: Atlas, 2000.

MAZZIONI, S.; DIEL, F. J.; OLIVEIRA, J. M. S. Atributos da qualidade da informação contábil em empresas participantes do mercado acionário brasileiro. Contabilidade, Gestão e Governança, v.19, n. 2, p. 230-253, 2016.

MEDEIROS, O. R.; DAHER, C. E. Testando a teoria de hierarquização de fontes de financiamento nas empresas brasileiras. Revista de Contabilidade e Finanças, v. 37, n. 1, p. 37-45, 2005.

OLIVEIRA, E. C. Determinantes do endividamento: evidência empírica para as empresas do distrito de Santarém. 2015. 61 p. Dissertação (Mestrado em Contabilidade e Finanças) Instituto Politécnico de Santarém, Escola Superior de Gestão e Tecnologia, Santarém, 2015.

OSHAGBEMI, T. Age influences on the leadership styles and behaviour of managers. Employee Relations, v. 26, n. 1, p. 14-29, 2004.

PENI, E. CEO and Chairperson characteristics and firm performance. Journal of Management and Governance, v. 18, n. 1, p.185-205, 2014. 
PEREIRA, B. S.; THEISS, V.; LUNKES, R. J.; SCHNORRENBERGER, D.; GASPARETTO, V.A. Relação entre as características observáveis dos CEOs e a remuneração. Contabilidad y Negocios, v. 11, n. 21, p. 5-24, 2016.

ROSTAGNO, L. M.; SOARES, K. T. C.; SOARES, R. O. O perfil fundamentalista das carteiras vencedoras e perdedoras na Bovespa no período de 1995 a 2002. BBR - Brazilian Business Review, v. 5, n. 3, p. 271-288, 2008.

SILVEIRA, A. D. M. Governança corporativa: o essencial para líderes. Rio de Janeiro: Elsevier, 2014.

TAVARES, A. L.; SILVA, C. A. T. A análise financeira fundamentalista na previsão de melhores e piores alternativas de investimento. Revista Universo Contábil, v. 8, n.1, p. 37-52, 2012.

VERGINI, D. P.; JACOMOSSI, F. A.; TURRA; S., HEIN, N. Impacto da responsabilidade social no desempenho econômico financeiro das empresas brasileiras componentes do Dow Jones Sustainability Index. Revista Eletrônica em Gestão, Educação e Tecnologia Ambiental Santa Maria, v. 19, n. 2, p. 879-898, 2015. 